\title{
Pentingnya Pelaksanaan Pendokumentasian Keperawatan Dalam Rumah Sakit
}

\author{
Nadia Febriani Br. Barus
}

Nadiafebriani001@gmail.com

Latar Belakang: Dokumentasi keperawatan merupakan bukti tertulis pelayanan yang diberikan kepada pasien oleh tenaga keperawatan yang bertujuan untuk menghindari kesalahan, tumpang tindih dan ketidak lengkapan informasi. Dalam asuhan keperawatan agar terbinanya koordinasi yang baik dan dinamis antar tenaga keperawatan serta meningkatkanefisiensi, efektifitas dan menjamin kualitas asuhan keperawatan. Dokumentasi keperawatan merupakan hal sangat penting, Manfaat pentingnya dokumentasi keperawatan adalah dapat digunakan sebagai bukti persidangan, gambaran kinerja pelayanan kesehatan yang diberikan, acuan dalam pendidikan tinggi keperawatan serta merupakan bahan pertimbangan dalam menentukan status pelayanan suatu institusi pelayanan kesehatan. Kegiatan pendokumentasian asuhan keperawatan sangat diperlukan dalam meningkatkan kualitas pelayanan. Menurut Dinarti, dkk (2009) pendokumentasian adalah pekerjaan mencatat peristiwa dan objek maupun aktifitas pemberian jasa (pelayanan) yang dianggap berharga dan penting. Dokumentasi adalah sesuatu yang tertulis tentang keadaan pasien secara komprehensif, pelayanan keperawatan yang diberikan, serta sebagai catatan tentang bukti bagi individu yang berwenang (Potter \& Perry, 2009). Pendokumentasian adalah pekerjaan mencatat tentang keadaan pasien secara komprehensif dan dapat dijadikan sebagai bukti. Banyak ahli yang memberikan definisi tentang dokumentasi keperawatan. Fisbach 1991 (dalam Ali 2010) mengatakan dokumentasi keperawatan adalah suatu dokumen yang lengkap, nyata, dan tercatat tentang tingkat kesakitan klien, jenis/tipe, kualitas dan kuantitas pelayanan. Dokumentasi asuhan keperawatan adalah catatan yang diarahkan untuk pengkajian, diagnosis, perencanaan, tindakan dan evaluasi (Ali, 2010). Dokumentasi keperawatan adalah catatan tentang kesehatan klien yang lengkap dan nyata. Kualitas dokumentasi keperawatan dilihat dari kepatuhan perawat terhadap aturan pendokumentasian yang ditetapkan oleh profesi atau pemerintah, misalnya kelengkapan dan keakuratan menuliskan asuhan keperawatan. Pendokumentasian asuhan keperawatan yang tidak lengkap dapat menurunkan mutu pelayanan di Rumah Sakit sehingga disarankan perawat dapat terus menjaga kualitas penulisan asuhan keperawatan sesuai dengan 
standar yang ditetapkan. Pendokumentasian asuhan keperawatan yang tidak lengkap mengakibatkan mutu Rumah Sakit akan menurun. Penelitian ini bertujuan untuk mengetahui gambaran kualitas pendokumentasian asuhan keperawatan.

Metode: Proses keperawatan memiliki tahapan yang bertujuan untuk menetapkan asuhan keperawatan yang professional kepada pasien. Dalam melaksanakan asuhan keperawatan, maka diperlukannya pendokumentasian yang tepat sebagi bukti legal dalam pelaksanaan layanan di rumah sakit. Pendokumentasian yang lengkap akan memberikan perlindungan kepada perawat terhadap asuhan keperawatan yang diberikan kepada pasien. Pelaksanaan proses keperawatan harus memperoleh kesinkronan hasil dari setiap proses keperawatan yang dilakukan oleh perawat. Maka pendokumentasian yang tepat sangat penting dilakukan dalam setiap tahapan proses keperawatan dalam asuhan keperawatan. Pendokumentasian yang tepat oleh perawat akan meningkatkan kualitas hasil asuhan keperawatan. merupakan suatu rangkaian kegiatan yang rumit dan sangat beragam serta memerlukan waktu yang cukup banyak dalam proses pembuatannya. Perkiraan waktu pembuatan dokumentasi asuhan keperawatan dapat mencapai 35-40 menit, hal ini dikarenakan seringnya perawat melakukan pencatatan yang berulang-ulang atau duplikatif. Walaupun demikian, terkadang dokumentasi keperawatan yang dihasilkan masih sering kurang berkualitas

Hasil:Dokumentasi Keperawatan merupakan bagian dari pelaksanaan Asuhan Keperawatan yang menggunakan proses keperawatan yang memiliki suatu nilai hukum yang sangat penting.Tanpa dokumentasi keperawatan maka semua implementasi keperawatan yang dilaksanakan oleh perawat tidak mempunyai makna dalam hal tanggung jawab dan tanggung gugat. Dokumentasi keperawatan dapat dikatakan sebagai pegangan untuk para perawat dalam mempertanggung jawabkan dan membuktikan pekerjaannya atau tindakan yang perawat lakukan.oleh sebab itu ada beberapa kaidah atau aturan yang harus ditaati oleh perawat didalam melakukan pendokumentasian perawatan ( Setiyarini, 2010 ) Saat ini Mutu pendokumentasian Asuhan Keperawatan yang di capai oleh Tim Mutu Keperawatan sebesar 59,71 \% di bawah target yang di tetapkan oleh Rumah sakit sebesar $70 \%$. Kurang nya mutu pendokumentasian perawatan yang dilakukan oleh para perawat saat ini dapat dikarenakan perubahan status instansi dari Rumah Bersalin menjadi Rumah Sakit Ibu Dan Anak, di mana hal pendokumentasian ini kurang dapat di mengertinya oleh para perawat - perawat lamadengan tingkat pendidikan SPK (sekolah Perawat Kesehatan ). Mutu pelayanan keperawatan sebagai indikator kualitas pelayanan kesehatan menjadi salah satu faktor penentu citra suatu institusi pelayanan kesehatan di mata 
masyarakat.( Nursalam Edisi 3 ) Salah satu indikator dari mutu pelayanan keperawatan itu adalah apakah pelayanan keperawatan yang di berikan itu memuaskan pasien atau tidak. Kepuasan merupakan perbandingan antara kualitas jasa pelayanan yang didapat dengan keinginan, kebutuhan dan harapan. ( Tjiptono 2001:54). Melihat Fenomena diatas, maka peneliti melakukan penelitian terhadap Hubungan Pendidikan perawat dengan mutu pendokumentasian asuhan keperawatan, agar pelayanan keperawatan dapat berjalan dengan baik dengan dilihat dari mutu asuhan keperawatan. Sejak tahun 70-an dokumentasi keperawatan menjadi sangat penting, dimana hal tersebut mencerminkan perubahan pada praktik keperawatan,hal ini berkaitan dengan kebutuhan suatu lembaga, dan pedoman hukum yang berlaku. Sejalan dengan pengelompokkan diagnosis yang berhubungan ( dignostic related groupings, DRG ), dokumentasi keperawatan semakin maju dan menjadi suatu mekanisme yang digunakan terhadap perawatan yang di berikan.

Pembahasan: Undang-Undang RI Nomor 44 Tahun 2009 tentang Rumah Sakit Pasal 52 menyatakan bahwa setiap rumah sakit wajib melakukan pencatatan dan pelaporan semua penyelenggaraan kegiatan rumah sakit dalam bentuk sistim informasi manajemen berupa pencatatan, penyimpanan, pelaporan dan pemusnahan dalam waktu tertentu sesuai peraturan perundang-undangan. Rumah sakit dalam pengelolaannya mempunyai pilar yang saling terkait satu sama lain yaitu: administrasi, manajemen berupa perencanaan setiap kegiatan, disiplin dari pelakunya, leadership dan kepemimpinan diri. Teori menyatakan "tulis apa yang ingin dilakukan, lakukan apa yang telah ditulis dan tulis apa yang telah dilakukan". Pelayanan yang diselenggarakan rumah sakit ada dua jenis yaitu pelayanan kesehatan dan administrative. Pelayanan administratif salah satunya adalah dokumentasi keperawatan yang berisi catatan keperawatan sebagai bukti pelaksanaan proses keperaw

atan dan catatan tanggapan/respon klien terhadap tindakan medis dan tindakan keperawatan yang telah dilaksanakan. Bagian integral manajemen rumah sakit berperan penting dalam meningkatkan mutu pelayanan berupa aspek administratif, hukum, keuangan, riset, edukasi serta dokumentasi. Kegiatan dokumentasi berupa menghimpun, mengolah, menganalisis dan menyimpan yang dijadikan sebagai informasi yang cukup penting dan diperlukan dalam membuat rencana program kerja untuk perkembangan organisasi. Dokumen digunakan sebagai bukti tertulis yang memiliki nilai hukum dan disimpan dalam waktu tertentu sebagai sumber keterangan, penyelidikan ilmiah, alat bantu bukti keabsahan suatu kegiatan.Keberhasilan jaminan mutu rumah sakit salah satu kuncinya adalah pemanfaatan data, dokumentasi kualitatif dan kuantitatif sebagai petunjuk dalam pengambilan keputusan secara internal oleh profesi kesehatan dalam organisasi rumah sakit. Mengingat pentingnya pelaksanaan 
dokumentasi keperawatan dalam bentuk sistim informasi manajemen berupa pencatatan, seharusnya Manajemen merupakan proses yang terdiri dari perencanaan, pengorganisasian, pengarahan dan pengendalian untuk mencapai tujuan. Dokumentasi merupakan bagian dariadministrasi sebagai jaminan pelayanan yang diberikan kepada pasien dan dapat mendukung kualitas pelayanan yang diberikan. Pelaksanaan manajemen dokumentasi keperawatan Sistem informasi secara luas dianggap sebagai kunci untuk meningkatkan kualitas pelayanan kesehatan. Kegunaan sistem informasi yaitu menyimpan data tentang semua kegiatan yang tujuan utamanya adalah untuk mempromosikan, memulihkan atau mempertahankan kesehatan. Sistem informasi dalam keperawatan merupakan dasar ilmu pengetahuan yang mengintegrasikan ilmu komputer dalam mengelola data, dan pengetahuan dalam praktek keperawatan. Sistem informasi dalam keperawatan merupakan komponen kunci dalam pemberian asuhan keperawatan modern .Pengaruh sistem informasi keperawatan pada kualitas pengolahan informasi keperawatan, hasil survey pertama diperoleh sebanyak $75 \%$ perawat merasa nyaman dalam menggunakan komputer dan survey kedua mengalami peningkatan menjadi 93\%, kemudian dilakukan survey sebelum dan sesudah, diperoleh perawat mengatakan sangat penting dokumentasi berbasis komputer. Dilakukan selanjutnya survey sebelum berdasarkan pengenalan komputer maka diperoleh perawat menghabiskan waktu $1 / 4$ dari waktu mereka untuk dokumentasi. Setelah dilakukan pelatihan secara signifikan meningkat menjadi $41 \%$. Berdasarkan efisiensi diperoleh, bahwa sebelumnya perawat merasa khawatir dapat mengurangi efesiensi, dilakukan survey sesudah terjadi peningkatan kualitas pengolahan informasi dalam keperawatan yaitu lebih cepat akses informasi, mudah merubah rencana keperawatan, menghindari dokumentasi tumpang tindih, dan penggunaan lebih mudah.Orlando menggunakan istilah proses keperawatan untuk menjelaskan asuhan keperawatan. Langkah-langkah dalam proses ini dikaitkan dengan metode ilmiah, seperti:pengumpulan data(pengkajian) merumuskan diagnosis, intervensi, implementasi dan evaluasi.

Kegiatan pendokumentasian keperawatan berdampak pada peningkatan mutu pelayanan asuhan keperawatan yang diberikan. Pendokumentasian keperawatan bermanfaat untuk meningkatkan kinerja perawat, meningkatkan kualitas pemberian asuhan keperawatan. Jika pendokumentasian dilaksanakan sesuai dengan standar dan format akan berdampak bagi kualitas pemberian asuhan keperawatan salah satunya meningkatkan mutu pelayanan yang diberikan ke pasien, selain itu juga untuk mengontrol asuhan keperawatan yang diberikan juga dapat dipertanggungjawabkan secara moral dan hukum pada perawat yang melaksanakan pendokumentasian. (P4)....." kalau misal dari rumah sakit ini sih dalam masalah dokumentasi kami masih melalui ini metode tertulis yang formatnya yang diberi kan oleh sesuai rumah sakit segala sesuatu 
sih di isi di situ yang kita lakukan ke pasien, apa yang mau kita rencanakan, e semuanya di tulis di dalam format itu". (P5)....." Waktu dan pasti akan ada loss!....... Loss informasi dan akhirnya nanti paling kita feedback ulang lagi itu". Faktor sarana penunjang yang disediakan rumah sakit termasuk format dokumentasi (naratif atau checklist) dan faktor perawat sebagai pelaksana. Lingkungan fisik termasuk fasilitas (format dokumentasi) dapat memberikan dampak signifikan terhadap kinerja perawat. Pencatatan data klien yang lengkap dan akurat akan memberikan kemudahan bagi perawat dalam membantu menyelesaikan masalah klien dan mengetahui sejauh mana masalah klien dapat teratasi, hal ini akan membantu meningkatkan mutu pendokumentasian asuhan keperawatan. Berdasarkan hasil analisis data penggunakan sistem pendokumentasi menggunakan metode paper base atau menulis tersebut membutuhkan waktu yang lama untuk menulis status pasien sehingga mempengaruhi kinerja dan pelayana keperawatan. Hal ini di karenakan instrument/format status pasien yang banyak dari pengkajian sampai evaluasi tindakan sehingga waktu yang dibutuhkan untuk menulis status pasien memakan waktu yang lama. Perawat menghabiskan waktu $1 / 4$ dari waktu mereka untuk menulis dokumentasi. Pengguna sistem informasi berperan dalam lintasan perawat dengan pasien dapat mengurangi hambatan klinis, seperti alur kerja, efesiensi dan kualitas pelayanan pasien rawat inap dapat meningkat. Penggunaan proses keperawatan sebagai kerangka kerja yang bermanfaat bagi pasien dan perawat Pendokumentasian dengan paper base dilaksanakan terus menerus akan berdampak bagi kualitas pemberian asuhan keperawatan salah satunya dapat menurunkan mutu pelayanan yang diberikan dengan kata lain pihak manajemen Rumah Sakit harus memperhatikan dan dapat mengatasi factor yang memengaruhi lamanya waktu dalam pendokumentasian seperti yang telah disebutkan di atas, maka waktu kerja perawat akan efisien, meningkatkan kualitas asuhan keperawatan dan mutu pelayanan. Dokumentasi keperawatan adalah setiap catatan baik tertulis maupun elektronik yang menggambarkan layanan keperawatan yang diberikan kepada klien dan dapat digunakan sebagai bukti bagi tenaga yang berwenang. Dokumentasi keperawatan yang berlaku di rumah sakit saat ini umumnya dilakukan secara tertulis (paper based documentation). Metode ini mempunyai kelemahana yaitu memerlukan waktu yang cukup lama untuk mengisi form yang tersedia, membutuhkam biaya percetakan form yang cukup mahal, sering hilang atau terselip, memerlukan tempat penyimpanan yang luas dan menyulitkan pencarian kembali saat diperlukan. Disamping itu masih banyak perawat yang tidak tahu data apa yang harus dimasukkan dan bagaimana dokumentasi keperawatan yang benar, untuk itu perlu adanya inovasi pencatatan dengan menggunakan pencatatan berbasis elektronik. Pencatatan berbasis elektronik telah lebih dahulu dilakukan oleh Negara negara maju, namun di Indonesia barudilakukan pada tahun 2000-an. Dokumentasi keperawatan berbasis elektronik ini memberikan 
keuntungan bagi perawat dalam hal waktu pendokumentasian yang lebih singkat, keterbacaan data dan kemudahan akses bila dibandingkan dokumentasi dalam format kertas. Pengembangan dokumentasi keperawatan berbasis elektronik tetap harus memperhatikan prinsip kerahasiaan data klien, komprehensif, akurat, tepat waktu, dan jelas mengidentifikasi pemberi perawatan sehingga perlu adanya kebijakan dan pedoman yang jelas bagi tenaga perawat dalam menjalankan sistem ini.

Dokumentasi adalah rekaman tertulis dan hukum dari intervensi yang menyangkut pasien dan itu mencakup serangkaian proses. Dokumentasi dibuat dengan catatan pribadi pasien, yang merupakan basis informasi tentang situasi kesehatannya. Pentingnya dokumentasi keperawatan adalah neuralgik, asalkan tanpa itu, tidak akan ada intervensi keperawatan kualitatif lengkap dan bahkan tidak ada perawatan yang efektif untuk pasien. Dalam tujuan dokumentasi keperawatan termasuk penelitian tentang perawatan yang lebih efektif dari masalah yang sudah terdeteksi, pemrograman perawatan melalui organisasi dan modifikasi rencana perawatan pasien dan komunikasi yang lebih langsung antara para profesional dari sistem kesehatan, yang berkolaborasi dalam perawatan pasien. Metode dokumentasi banyak dan di antara yang paling mendasar adalah metode yang diarahkan pada sumber atau masalah, sistem masalah-intervensievaluasi, registrasi terfokus, diagram fokus, registrasi dengan pengecualian, file elektronik dan rumah dokumentasi. File pasien harus menggambarkan situasinya saat ini dan mencerminkan keseluruhan proses keperawatan.

Penutup :Kepuasan perawat dalam pendokumentasian asuhan keperawatan sebagian besar menyatakan tidak puas sebanyak $58 \%$, perawat yang menyatakan ketidakpuasan atau sebagian tidak setuju melakukan pendokumentasian asuhan keperawatan dalam penelitian ini tentang dokumentasi melindungi perawat dari hukum sebanyak $55,6 \%$. Persepsi perawat yang merasa puas maupun tidak puas tetap melakukan pendokumentasian asuhan keperawatan menggunakan SIMRS dengan kualitas relevansi $(98,8 \%)$, akurasi $(98,8 \%)$ dan ketepatan waktu yang baik $(97,5 \%)$. Namun persepsi perawat pada kualitas pada aspek kelengkapan perawat masih kecil dalam melakukan pendokumentasian asuhan keperawatan menggunakan SIMRSyang baik $(40,7 \%)$.

Dokumentasi keperawatan merupakan salah satu bagian penting dalam proses asuhan keperawatan. Namun pada kenyataannya sering kita temukan dokumentasi keperawatan kurang lengkap dan tidak dapat dipertanggungjawabkan, bahkan cenderung diabaikan. Untuk mengatasi masalah tersebut perlu dilakukan adanya suatu 
perubahan dalam system pendokumentasian. Penerapan sistem informasi keperawatan dalam dokumentasi asuhan keperawatan bertujuan untuk meningkatkan kuantitas dan kualitas dokumentasi asuhan keperawatan. Agar dapat menghasilkan dokumentasi yang berkualitas maka perawat membutuhkan dukungan melalui pendidikan agar mengetahui langkah-langkah untuk menghubungkan diagnosa dengan intervensi, spesifik ke etiologi diidentifikasi, dan untuk mengidentifikasi hasil asuhan keperawatan. Selain dukungan tersebut diatas, untuk meningkatkan kualitas dokumentasi asuhan keperawatan perawat juga perlu didukung dalam aplikasi perangkat lunak, serta dalam melaksanakan konsep keperawatan dan menerapkan proses keperawatan. Sebelum menerapkan sistem tersebut, faktor manusia dan pengaturan lingkungan tertentu perlu dipertimbangkan dan dianalisis terlebih dahulu agar implementasinya sukses dan terjadi peningkatan kualitas dalam jangka panjang.

Daftar pustaka

1. Simamora, R. (2009). Dokumentasi Proses Keperawatan.

2. Simamora, R. H., Purba, J. M., Bukit, E. K., \& Nurbaiti, N. (2019). Penguatan Peran Perawat Dalam Pelaksanaan Asuhan Keperawatan Melalui Pelatihan Layanan Prima. JPPM (Jurnal Pengabdian Dan Pemberdayaan Masyarakat), 3(1), 25-31

3. Dewi Rosmalia, Rizanda Machmud \& Haryadi Mangkuto.2015. Analisis Sistim Manajemen Dokumentasi Keperawatan pada Poliklinik Gigi Rumah Sakit di Bukittinggi. Jurnal kesehatan andalas.vol 4 no 3 
4. Amalia,Hema Malini \&, Sri Yulia.2018.KEPUASAN PERAWAT TERHADAP KUALITAS PENDOKUMENTASIAN ASUHAN KEPERAWATAN. Jurnal Keperawatan Indonesia, Volume 21 No.3

5. Dyah Fitri Wulandari \& ,Hanny Handiyani.2019. PENGEMBANGAN DOKUMENTASI KEPERAWATAN BERBASIS ELEKTRONIK DI RS X KOTA DEPOK DENGAN MENGGUNAKAN TEORI PERUBAHAN LEWINS. Jurnal Keperawatan Global, Volume 4, No 1

6. Supratti \&, Ashriady.2019.PENDOKUMENTASIAN STANDAR ASUHAN KEPERAWATAN DI RUMAH SAKIT UMUM DAERAH MAMUJU, INDONESIA.jurnal kesehatan manarang. Volume 2, Nomor 1.

7. Niken Yuniar Sari2. 2018.Metode Pendokumentasian Elektronik dalam Meningkatkan Kualitas Pelayanan Keperawatan Jurnal Kesehatan Volume 9, Nomor 3,

8. Mulyaningsih.2012.Meningkatkan Kualitas Dokumentasi Asuhan Keperawatan Dengan Sistem Informasi Keperawatan Berbasis Komputer. J. Ilmu dan Tek. Kesehatan (JITK), Vol. 2, No. 1

9. Muryani, Endang Pertiwiwati, Herry Setiawan. 2019.KUALITAS PENDOKUMENTASIAN ASUHAN KEPERAWATAN DIRUANG RAWAT INAP(Studi di RSUD Kalimantan Tengah).vol2.no1

10. Renny Nova Goni \& Octava Girsang, Peekie Rondonuwu HUBUNGAN MOTIVASI PERAWAT DENGAN KEPATUHAN PENDOKUMENTASIAN ASUHAN

KEPERAWATAN DI RUANGAN PERAWAT PENYAKIT DALAM RSUD NOONGAN RELATIONSHIPS WITH MOTIVATIONAL NURSES NURSING DOCUMENTATION 
COMPLIANCE IN THE ROOM NURSES NOONGAN DISEASE HOSPITAL , E-Jurnal Sariputra.vol 5 no 1

11. Suryati, 2014, Hubungan Motivasi Perawat Dengan Pelaksanaan AsuhanKeperawatan Di Ruangan Rawat Inap RSUD Pasar Rebo. Jurnal health Quality, vol 5. No 1.

12. Ehrenbrg, A., \& Ehnforg, M. (2012). Patient problems, needs, and nursing diagnoses in Swedish Nursing Home records. Nursing Diagnosis, 10 (2), 